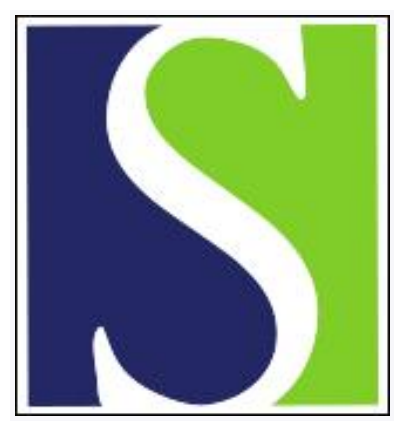

Scand J Work Environ Health 1980;6(1):58-65

https://doi.org/10.5271/sjweh.2633

Issue date: Mar 1980

Reactions to hand cooling in workers occupationally exposed to cold.

by Enander A, Sköldström B, Holmér I

Key terms: adaptive response; cold; hand cooling; occupational exposure; pain; reaction; skin temperature; thermal sensation; worker

This article in PubMed: www.ncbi.nlm.nih.gov/pubmed/7384768

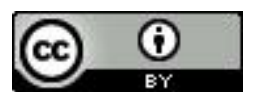




\title{
Reactions to hand cooling in workers occupationally exposed to cold
}

\author{
by Ann Enander, MA, Björn Sköldström, MSc, and Ingvar Holmér, $\mathrm{PhD}{ }^{1}$
}

\begin{abstract}
ENANDER A, SKÖLDSTRÖM B, HOLMER I. Reactions to hand cooling in workers occupationally exposed to cold. Scand $j$ work environ health 6 (1980) $58-65$. Ten men occupationally exposed to cold and ten office workers participated in the study. Reactions to immersion of the hands in cold water $\left(+10^{\circ} \mathrm{C}\right)$ for 2 min were studied during the following $30 \mathrm{~min}$ at two different ambient temperatures, 10 and $20^{\circ} \mathrm{C}$. Hand skin temperature was recorded in thermograms, and the subjects rated cold sensation and pain. Considerable interindividual differences in hand skin temperature reaction were found in both groups. On the average the occupationally exposed workers had a somewhat higher hand skin temperature than the office workers during the recovery period in the $10^{\circ} \mathrm{C}$ ambient temperature, although the difference did not reach significance. The office workers rated significantly greater cold sensation as a result of the cold immersion, especially during an ambient temperature of $10^{\circ} \mathrm{C}$, and the frequency of pain ratings was higher for this group. The results suggest that cooling among the occupationally exposed workers at work was not severe enough to produce physiological adaptations, although some psychological adaptation was indicated.
\end{abstract}

Key terms: adaptive responses, hand cooling, pain, skin temperature, thermal sensation.

Exposure of the hands to cool or cold ambient conditions while the rest of the body is subjected to a comfortable microclimate occurs in some occupational activities (2, $3,5,6,9,11,12,14)$. Many kinds of outdoor activities in the winter, as well as work in cold stores, may produce longlasting, repeated exposures with hand skin temperatures below $20^{\circ} \mathrm{C}$ and finger skin temperatures below $15^{\circ} \mathrm{C}(3,14)$.

Adaptive responses to local cooling of the hands have been reported in many investigations [for reviews see Carlson et al (1) and Hellström (6)]. Adaptation is the most obvious in populations permanently exposed to cold (Eskimos, Lapps, Arctic Indians, etc), eg, they have a quicker onset

1 Department of Occupational Health, National Board of Occupational Safety and Health, Solna, Sweden.

Reprint requests to: Dr Ingvar Holmér, National Board of Occupational Safety and Health, S-171 84 Solna, Sweden. and a higher frequency of cold-induced vasodilatation $(2,9)$. Although similar findings have been obtained from fishermen (9), fish filleters (11) and ice-chamber workers (17), occupational exposure to cold in general is less severe and involves smaller adaptive responses $(3,6,16,17)$. Hand blood flow and cold-induced vasodilatation did not differ significantly in groups exposed to cold occupationally in comparison with the referents studied by Hellström (6). In the same study (6) however the cold-exposed group maintained a higher hand skin temperature and perceived pain at lower hand skin temperatures in comparison with nonexposed individuals.

The purpose of the present study was to investigate the extent to which men occupationally exposed for many years to a moderately cold climate $\left(+5\right.$ to $\left.+10^{\circ} \mathrm{C}\right)$ display physiological or psychological adaptations similar to those found in more severe cold exposure in response to local cooling. 


\section{Material and methods}

\section{Subjects}

A total of 20 male subjects participated in the study; 10 of the subjects were workers exposed to cold (approx $+10^{\circ} \mathrm{C}$ ) in the meat-cutting and packaging departments of a slaughterhouse. Age and exposure data for this group are given in table 1 . Included also are the lowest hand and finger skin temperatures of some of the workers as measured during a normal workday in a separate study (3). The remaining 10 subjects were a reference group of office workers matched according to age (table 1). These subjects were no more acclimatized to cold than could be expected for the time of year (NovemberDecember). There were six smokers in the cold-exposed group and five in the reference group.

\section{Experimental procedure}

In the experiment the subjects' hands were exposed to a cold test under two different climatic conditions, ambient temperature +10 and $+20^{\circ} \mathrm{C}$. The two sessions were run consecutively, and the sequence was reversed for half of the subjects in each group. For sessions at $20^{\circ} \mathrm{C}$ the subjects wore a short-sleeved cotton T-shirt, white cotton slacks and jacket, underpants, socks and shoes. At $10^{\circ} \mathrm{C}$ the standardized clothing was supplemented by thermal trousers and a thermal jacket.

Before the start of the experiment the subjects received information on the study and instructions concerning the procedure. During the 30-min break between sessions the subjects completed a questionnaire regarding, eg, health status, previous hand injuries, experience of cold exposure and frost bite, etc.

The cold test used in the study consisted of immersing rubber-gloved hands up to the wrists in cold water $\left(+10^{\circ} \mathrm{C}\right)$ for 2 min (18). Thermograms of the palmar surface of the dry, naked hands were taken immediately prior to immersion (upon entering the climate chamber) and after 0.5 , 2 , and then every fourth minute up to 30 min after the immersion. During this time the subjects remained seated and kept their hands still at waist level. Immediately after each thermogram the subjects were requested to rate their perception of temperature and pain in the hands.

\section{Measurements}

The experimental sessions were conducted in a climate chamber with controlled air temperature $\left( \pm 0.5^{\circ} \mathrm{C}\right)$, relative humidity $(40 \%$ ) and air velocity (less than $0.2 \mathrm{~m} / \mathrm{s}$ ). Body temperature was measured with a rectal thermometer at the start of the ex-

Table 1. Age and exposure data for the two groups. Lowest finger and hand skin temperatures measured during normal work are reported for the occupationally exposed group (3).

\begin{tabular}{|c|c|c|c|c|c|}
\hline \multirow{3}{*}{$\begin{array}{l}\text { Subject } \\
\text { number }\end{array}$} & \multicolumn{4}{|c|}{ Occupationally exposed group } & \multirow{3}{*}{$\begin{array}{c}\begin{array}{c}\text { Reference } \\
\text { group }\end{array} \\
\begin{array}{c}\text { Age } \\
\text { (a) }\end{array}\end{array}$} \\
\hline & \multirow{2}{*}{$\begin{array}{l}\text { Age } \\
\text { (a) }\end{array}$} & \multirow{2}{*}{$\begin{array}{l}\text { Exposure } \\
\text { (a) }\end{array}$} & \multicolumn{2}{|c|}{ Skin temperature $\left({ }^{\circ} \mathrm{C}\right)$} & \\
\hline & & & Finger & Hand & \\
\hline 1 & 61 & 20 & 20 & 23 & 65 \\
\hline 2 & 56 & 30 & 22 & 28 & 58 \\
\hline 3 & 54 & 17 & 14 & 20 & 54 \\
\hline 4 & 53 & 14 & 18 & 23 & 52 \\
\hline 5 & 47 & 30 & - & - & 46 \\
\hline 6 & 47 & 30 & - & - & 40 \\
\hline 7 & 33 & 13 & - & - & 32 \\
\hline 8 & 28 & 11 & 25 & 26 & 28 \\
\hline 9 & 22 & 3 & - & 二 & 25 \\
\hline 10 & 21 & 4 & 20 & 22 & 23 \\
\hline Mean & 42 & 17 & 19.8 & 23.7 & 42 \\
\hline SD & 15 & 10 & 3.7 & 2.9 & 15 \\
\hline
\end{tabular}


periment, between the two sessions, and at the end of the experiment. Temperature was rated on a 19-point scale with verbal definitions on every second point as follows:

Very, very warm
Very warm
Warm
Somewhat warm
Neither warm nor cold
Somewhat cold
Cold
Very cold
Very, very cold

Pain was rated on a continuous scale with five verbally defined points, ranging from no pain to unbearable pain.

The thermography equipment consisted of an AGA Thermovision System mod $680 / 102 \mathrm{~B}$, operated at a sensitivity of approximately $2{ }^{\circ} \mathrm{C}$ per color with a total temperature range from 14 to $34^{\circ} \mathrm{C}$. A temperature reference, AGA mod 1010, set at a temperature of $30^{\circ} \mathrm{C}$, was used for system calibration and in the thermograms. Each thermogram depicted the hands in up to 10 different colors according to skin temperature.

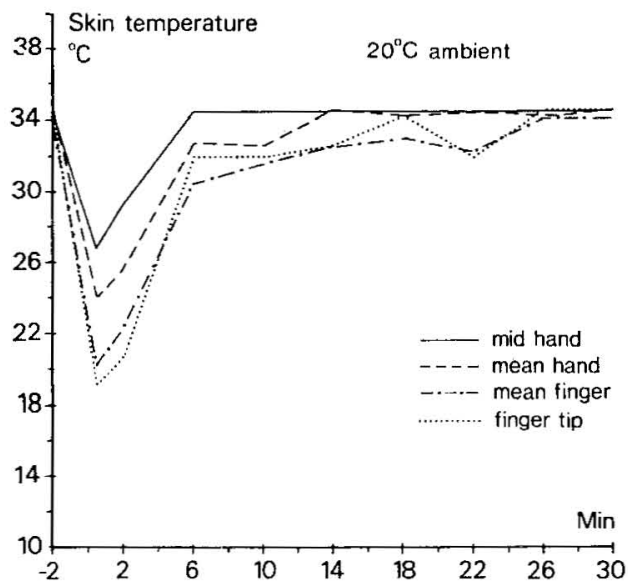

\section{Evaluation and analysis}

Each thermogram was evaluated with regard to 22 points on each hand as shown in fig 1 . The temperature value corresponding to the color/colors at each point was determined (accuracy $\pm 1^{\circ} \mathrm{C}$ ) and typed into a minicomputer (Alpha LSI-2). The following variables were calculated on both hands for further analysis: mean fingertip temperature (points 1-4), mean finger temperature (points 1-14), mean

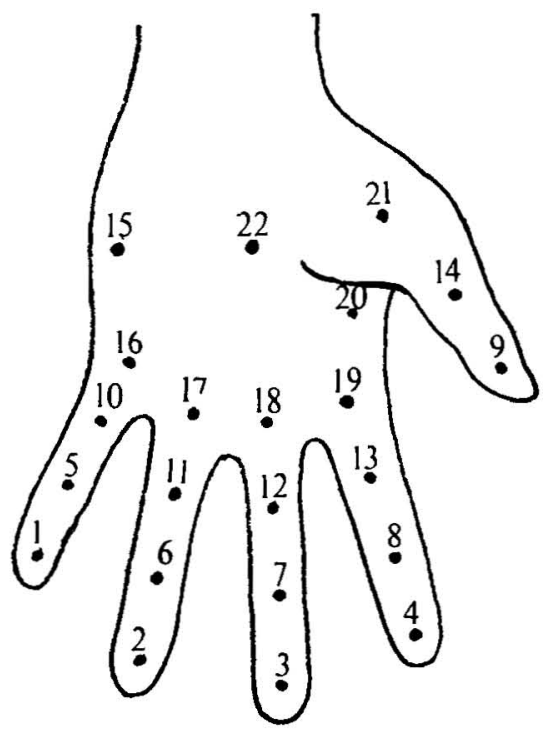

Fig 1. Location of the 22 points used in evaluating the thermograms of the hand.

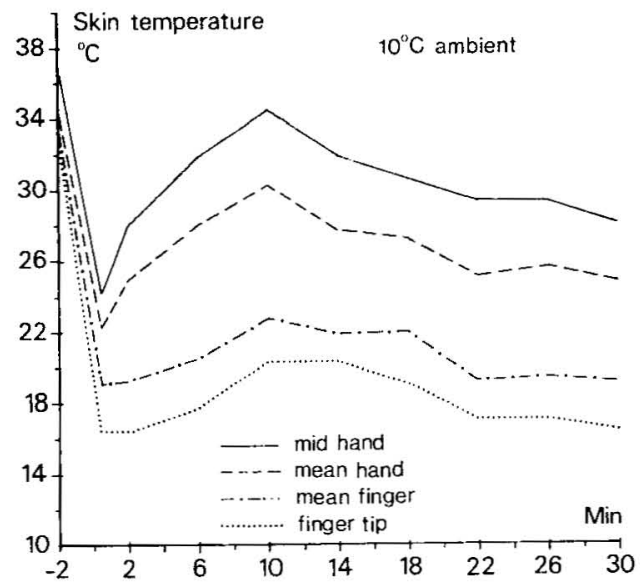

Fig 2. Change in hand skin temperature on the right hand of one occupationally exposed subject. 
hand temperature (points 15-22) and midhand temperature (point 22). Each individual temperature point weighed equally in the calculation.

For the statistical analysis of skin temperature and perceived temperature data a three-way analysis of variance model with repeated measurements on two factors was used (20). Group, ambient temperature, and measurement occasion constituted the three sources of variation.

\section{Results}

\section{General reaction pattern}

After a considerable drop following the cold water immersion, the change in hand skin temperature during recovery displayed great interindividual variation. In some subjects there was a more or less pronounced negatively accelerated increase in temperature with time; the increase brought some of the temperatures, but not all, back to the preimmersion level within $30 \mathrm{~min}$. In other subjects hand skin temperature remained nearly constant at the first postimmersion value during the entire recovery period. This latter reaction was more frequent when recovery took place in an ambient temperature of $10^{\circ} \mathrm{C}$, as compared to $20^{\circ} \mathrm{C}$. Fig 2 illustrates the temperature reaction in different parts

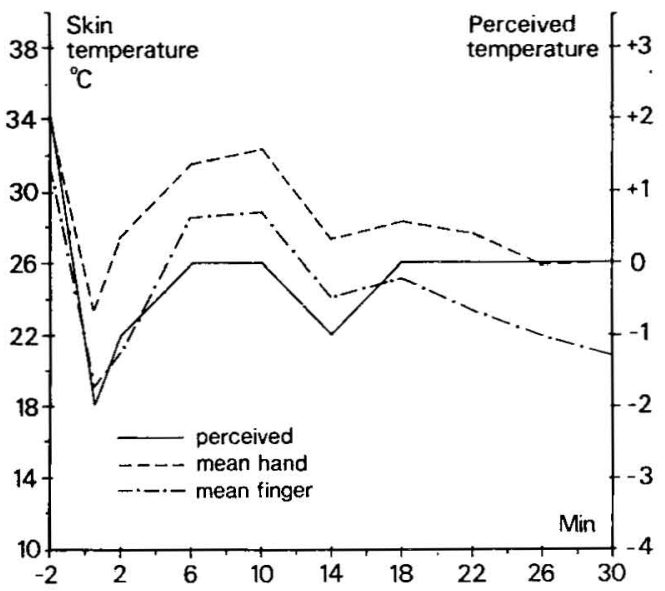

Fig 3. Hand skin temperatures and perceived temperature in the hand of one occupationally exposed subject during a session with an ambient temperature of $10^{\circ} \mathrm{C}$. of the hand of one subject in the two environments.

No relationship could be observed between changes in hand skin temperature and body temperature, age, number of years of exposure to cold, or smoking habits. Neither were there any systematic differences in the response of the two hands to the immersion and recovery procedure. Cooling was in no case sufficient to elicit vasodilatation.

The perceived temperature of the hands closely followed the variation in the objectively measured temperatures of most of the subjects. Even quite small variations in finger temperature could cause a change in perception. Fig 3 illustrates the finger temperature and perceived temperature for one subject during an experimental session. Several subjects indicated a subjective difference in the temperature of the two hands, or in the different fingers of one hand, which in most cases could be found also in the thermograms.

\section{Comparison between groups}

Apart from a markedly higher frequency of cuts and injuries of the hands among the occupationally exposed group, no differences between the groups as regards health status or other factors were revealed in the responses to the questionnaire.

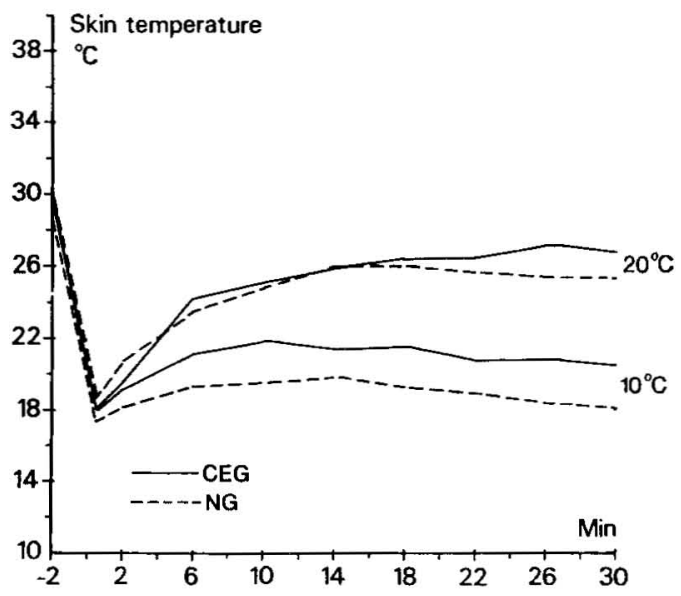

Fig 4. Mean finger tèmperature of the right hands of both groups (CEG = occupationally cold-exposed group, $\mathrm{NG}=$ occupationally nonexposed group) at ambient temperatures of 10 and $20^{\circ} \mathrm{C}$. 


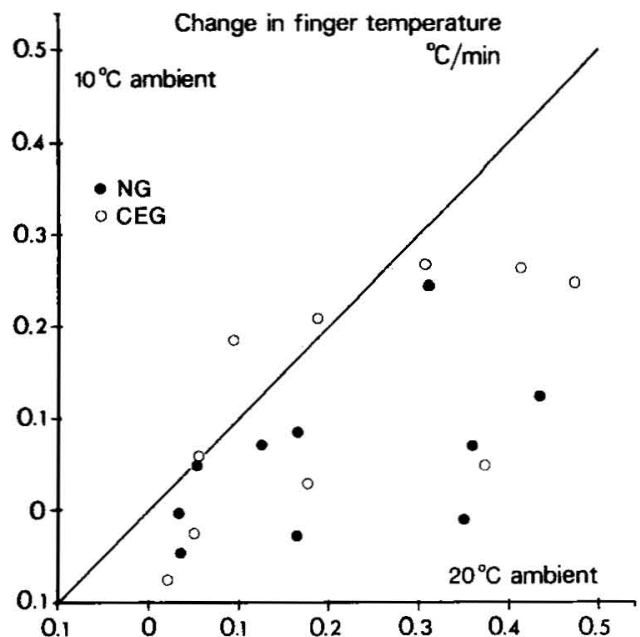

Fig 5. Mean change in finger temperature per minute during rewarming in an ambient temperature of $10^{\circ} \mathrm{C}$ in comparison with $20^{\circ} \mathrm{C}$. Each point represents one subject. ( $N G=$ occupationally nonexposed subject, CEG = occupationally cold-exposed subject)

Table 2. F-ratios and degrees of freedom (df) obtained in the analysis of variance of perceived temperature ratings for the right hand in response to cold immersion. The analysis was performed on the values before and immediately after immersion.

\begin{tabular}{lcc}
\hline Source of variation & $\mathrm{df}$ & F-ratio \\
\hline Group (G) & $1 / 18$ & $6.58^{*}$ \\
Ambient temperature (A) & $1 / 18$ & $4.92^{*}$ \\
Measurement occasion (M) & $1 / 18$ & $112.79^{* * *}$ \\
$\mathrm{G} \times \mathrm{A}$ & $1 / 18$ & $<1$ \\
$\mathrm{G} \times \mathrm{M}$ & $1 / 18$ & 1.69 \\
$\mathrm{~A} \times \mathrm{M}$ & $1 / 18$ & 1.00 \\
$\mathrm{G} \times \mathrm{A} \times \mathrm{M}$ & $1 / 18$ & $6.05^{*}$ \\
\hline$* \mathrm{p}<0.05, * * \mathrm{p}<0.01, * * *<0.001$.
\end{tabular}

The two groups demonstrated a similar decrease in mean finger skin temperature during immersion. The interindividual variation in reactions during recovery was considerable within both groups. As illustrated in fig 4, the mean temperature of the occupationally exposed group was however consistently higher than that of the reference group during recovery. This difference in reaction between the groups remained for all the temperature variables studied, but only under the $10^{\circ} \mathrm{C}$ conditions. No differences were observed at an ambient temperature of $20^{\circ} \mathrm{C}$. In the analysis of variance of finger skin temperature data during recovery, no differ-

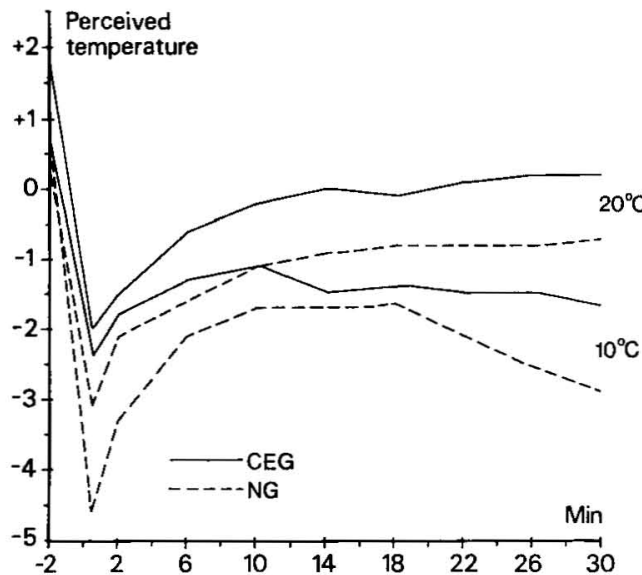

Fig 6. Mean perceived temperature ratings for the right hand for both groups (CEG = occupationally cold-exposed group, NG = occupationally nonexposed group) at ambient temperatures of 10 and $20^{\circ} \mathrm{C}$

ences between the groups or interaction with groups reached significance.

The average change in finger temperature per minute was calculated for each individual and is given in fig 5. Almost all subjects in both groups showed a smaller rate of increase in temperature when the ambient temperature was $10^{\circ} \mathrm{C}$ than when it was $20^{\circ} \mathrm{C}$. The groups differed somewhat at $10^{\circ} \mathrm{C}$ in that five subjects in the occupationally exposed group had a value of $0.16^{\circ} \mathrm{C} / \mathrm{min}$ or higher, as compared to only one subject in the reference group.

Fig 6 shows the mean perceived temperature ratings for the right hand for both groups at the ambient temperatures of 10 and $20^{\circ} \mathrm{C}$. The analysis of variance of the subjective reaction to the cold immersion (values before and immediately after the immersion, table 2) disclosed a significant difference between the groups $(p<0.05)$ and a significant interaction between the groups, climate and time $(p<0.05)$. The reference group felt somewhat colder than the occupationally exposed group in both climate types, and this difference was especially marked after the cold immersion at $10^{\circ} \mathrm{C}$. For both groups there was a significant difference in ratings between the two climate types 
$(p<0.05)$ and, naturally, before and after immersion $(p<0.001)$.

The analysis of variance of perceived hand temperature over the entire recovery phase (values from 0.5 to $30 \mathrm{~min}$ after immersion) showed no significant differences as regards the groups or interactions with the groups. During recovery the mean temperature rating was somewhat higher for the occupationally exposed than for the reference group in an ambient temperature of both 10 and $20^{\circ} \mathrm{C}$ (fig 6). However, the wide interindividual range in temperature reaction during the recovery phase was accompanied by a considerable variation in the perception rating of both groups.

Most subjects in both groups felt some pain in the hands during the immersion test, although the pain often decreased rapidly after they removed their hands from the cold water. Immediately after the cold immersion there was a greater frequency of pain ratings among the referents in an ambient temperature of both 10 and $20^{\circ} \mathrm{C}$ (7 and 6 out of 10 , respectively) than among the occupationally exposed group (4 and 2 out of 10 , respectively). These differences did not, however, reach significance when tested with the chi-square test (13). A few subjects in both groups indicated slight pain throughout the recovery phase.

\section{Discussion}

The hands show the most pronounced adaptations after prolonged exposure to cold environments with, eg, modifications in the onset, frequency, and magnitude of cold-induced vasodilatation and maintained higher levels of skin temperature in response to local cooling $(1,6)$. A key factor in the occurrence of adaptation is that the tissues are actually cooled for some time and with sufficient intensity. Furthermore, the nature and extent of adaptation are dependent on the interaction of local temperature, mean skin temperature, and body core temperature $(1,19)$. Unfortunately, many studies on habituation to cold present no other data on conditions of exposure than the air temperature of the environment. Under such circumstances it is difficult to assess the actual factor stimulating the habituation process. This may be one explanation for the discrepancy of results from different studies as reviewed by Hellström (6).

Cold-induced vasodilatation was not studied in our subjects since the water bath test was too short and too small a cooling stimulus to evoke it (8). Since the occupationally exposed group was accustomed to a relatively moderate cold climate, a less severe cold test was chosen.

No significant differences in hand skin temperatures were found between the two groups in this study. The occupationally exposed group did however tend to have higher hand skin temperatures in the $10^{\circ} \mathrm{C}$ environment than the referents did. This tendency is in accordance with previous results $(6,11,16,17)$.

Apparently, the absence of any significant physiological adaptation of the occupationally exposed groups can be explained by the fact that cold stress was not severe enough to produce tissue cooling stimulating the habituation process. This conclusion is supported by Tanaka (17), who reported smaller adaptations in coolroom workers in comparison with, eg, icechamber workers and swimmers.

In six of the ten subjects of the occupationally exposed group in this study, skin temperatures were monitored on two different occasions during a normal workday (3). The average hand and finger temperatures were 23.7 and $19.8^{\circ} \mathrm{C}$, respectively, with great interindividual variations (table 1). In the same study it was found that body core temperature remained almost constant and normal during the observation period (3). At higher rates of work in ambient temperatures of $0-10^{\circ} \mathrm{C}$ with appropriate clothing it is easier to maintain thermal balance and reduce, or even prevent, peripheral cooling of, eg, hands and feet. Under the same conditions the rewarming of cold hands and feet can take place (7) and has been found to be quicker and more pronounced in cold-exposed outdoor workers (16).

On the other hand the relatively high hand and finger skin temperatures observed during normal work can be a result of acclimatization. Glaser \& Shephard (4) clearly showed that hand skin temperatures fell progressively less during succes- 
sive exposure to cold (air temperature 3 $6^{\circ} \mathrm{C}$ ) in lightly clad, resting subjects, averaging $15.5^{\circ} \mathrm{C}$ on the 11 th day. This hand skin temperature is about $5^{\circ}$ lower than that measured for six of our subjects during work.

In both climates the occupationally exposed group rated hand temperature as less cold than did the referents. The question remains as to whether this reflects a difference in perception or in the use of the rating scale per se between the two groups. The subjects' previous experience of the stimulus dimension to be evaluated should be considered when different groups are compared with verbal definition scales. All the occupationally exposed subjects in this study had been repeatedly exposed to low hand temperatures, and this exposure could have conceivably resulted in a shift in the meaning attached to the verbal definitions used on the temperature scale as compared to the referents' responses.

Regardless of the level at which the subjects set their ratings, the referents showed a significantly greater change in perceived temperature in response to immersion at $10^{\circ} \mathrm{C}$. No such differences were found at $20^{\circ} \mathrm{C}$, and only the referents rated a greater drop in temperature in $10^{\circ} \mathrm{C}$ than in $20^{\circ} \mathrm{C}$. Since there were no corresponding differences in mean hand temperature in response to immersion, it would seem reasonable to attribute these results to differences in experience with cold between the groups. It can be hypothesized that a low ambient temperature to which subjects are unaccustomed has the effect of increasing the subjective reaction to local cooling in comparison with that of subjects accustomed to cold exposure.

Evidence of experimentally induced adaptation to cold pain has been shown in several studies $(10,15)$. Hellström (6) found a lower frequency of pain reaction in outdoor than in indoor workers within the same finger temperature range. A similar, but nonsignificant, tendency was found in the present study between the two groups, although the cold immersion test was less severe than that usually used in studies of cold pain.

To summarize, local cooling of the hands with occupational cold exposure in the present study was not severe enough to produce significant physiological adaptation. There was however some evidence of a psychological adaptation to cold sensation and pain among the cold-exposed workers studied.

\section{Acknowledgment}

This study was part of a project with the objective of studying the effect of work in a cold climate on man. The project has been supported by grants from the Swedish Work Environment Fund (74/176).

\section{References}

1. Carlson LD, Hsieh ACL. Cold. In: Edholm OG, Bacharach AL, ed. The physiology of human survival. Academic Press, London 1965, pp 15-51.

2. Elsner RW, Nelms JD, Irving LW. Circulation of heat to the hands of Arctic Indians. J appl physiol 15 (1960) 662-666.

3. Enander A, Ljungberg A-S, Holmér I. Effects of work in cold stores on man. Scand j work environ health 5 (1979) 195-204.

4. Glaser EM, Shephard RJ. Simultaneous experimental acclimatization to heat and cold in man. J physiol (London) 169 (1963) 592602.

5. Goldsmith R. Cold exposure of farm and laboratory workers. J appl physiol 22 (1967) $47-49$.

6. Hellström B. Local effects of acclimatization to cold in man. Universitetsforlaget, Oslo 1965.

7. Hellström B, Berg $K$, Vogt Lorentzen F. Human peripheral rewarming during exercise in the cold. J appl physiol 29 (1970) 191-199.

8. Kramer K, Schultze W. Die Kältedilatation der Hautgefässe. Pflügers Arch 25 (1948) $141-170$.

9. Krog J, Folkow B, Fox RH, Lange Anderson $K$. Hand circulation in the cold of Lapps and North-Norwegian fishermen. $J$ appl physiol 15 (1960) 654-658.

10. Leblanc $J$, Potvin P. Studies on habituation to cold pain. Can $\mathbf{j}$ physiol pharmacol 44 (1966) 287-293.

11. Nelms JD, Soper DJG. Cold vasodilatation and cold acclimatization in the hands of British fish filleters. J appl physiol 17 (1962) $444-448$.

12. O'Neill DH. Thermal comfort in milking parlours. Appl ergon 9 (1978) 223-230.

13. Siegel S. Nonparametric statistics for the behavioral sciences. McGraw-Hill Book Co, Tokyo 1956.

14. Steegman AT Jr. Finger temperatures during work in natural cold: the Northern Ojibwa. Hum biol 49 (1977) 349-362.

15. Strempel H. Adaptive Modifikationen des Kältesschmerzes. Eur j appl physiol 36 (1976) $19-25$. 
16. Strömme S, Lange Andersen $K$, Elsner RW. Metabolic and thermal responses to muscular exertion in the cold. $J$ appl physiol 18 (1963) 756-763.

17. Tanaka M. Experimental studies on human reaction to cold. Bull tokyo med dent univ 18 (1971) 269-280.

18. Tromp SW. A simple water bath test for estimating the thermoregulation efficiency of man. Int $j$ biometeorol 7 (1964) 291-296.

19. Werner I. Influences of local and global temperature stimuli on the Lewis reaction. Pflügers arch 367 (1977) 291-294.

20. Winer BJ. Statistical principles in experimental design. McGraw-Hill Book Co, New York, NY 1970.

Received for publication 11 October 1979 